\title{
Insulin-like growth factor II gene expression in the fetus and placenta of the horse during the first half of gestation
}

\author{
S. N. Lennard ${ }^{1}$, F. Stewart ${ }^{1,2}$ and W. R. Allen ${ }^{1}$ \\ ${ }^{1}$ Thoroughbred Breeders' Association Equine Fertility Unit, Mertoun Paddocks, Woodditton Road, \\ Newmarket, Suffolk CB8 9BH, UK; and ${ }^{2}$ The Babraham Institute, Babraham, Cambridge CB2 4AT, UK
}

\begin{abstract}
Placentation in equids involves two types of trophoblast: a minor invasive component, the chorionic girdle, that gives rise to transient endocrine structures known as endometrial cups, and a major non-invasive component, the allantochorion, that forms the diffuse, microcotyledonary placenta. Growth factors are likely to be important in controlling these complex events at implantation and this study describes the use of in situ hybridization and northern blotting techniques to monitor expression of insulin-like growth factor II (IGF-II) in the fetus and placenta of the horse (Equus caballus), using 12 conceptuses recovered between 14 and 150 days of gestation (term is about 340 days). The anti-sense, but not the sense, ovine IGF-II oligonucleotide probe ( 45 mer) hybridized to a total of seven IGF-II mRNA transcripts $(6.2-1.3 \mathrm{~kb})$ in RNA extracted from horse fetal liver, demonstrating the specificity and validity of the probe for equine IGF-II mRNA. In situ hybridization demonstrated that the IGF-II gene was expressed intensely in the fetus at all stages examined, predominantly in tissues of mesodermal origin, but also in the endoderm-derived liver and epithelia of the gut and lung bronchioles, and the ectoderm-derived facial mesenchyme and choroid plexus. High concentrations of IGF-II mRNA were also detected in the extraembryonic mesoderm, invasive chorionic girdle and mature endometrial cup tissue. There was no signal in the maternal endometrium at any stage of pregnancy. Higher concentrations of IGF-II message in the invasive chorionic girdle than the non-invasive trophoblast at the time of invasion suggests that IGF-II promotes invasiveness of trophoblast, as proposed in humans. Furthermore, increased concentrations in the allantochorion after implantation suggest a possible role in the development of the epitheliochorial placenta.
\end{abstract}

\section{Introduction}

The insulin-like growth factors (IGFs) I and II are single chain polypeptides of approximately $7.5 \mathrm{kDa}$ that have mitogenic and differentiating effects on a diversity of somatic cell types. The actions of IGFs are mediated primarily through the type I IGF receptor (Humbel, 1990) and they are modulated by a complex series of binding proteins (Baxter and Martin, 1989). IGF-II is expressed predominantly in the fetus and its role in the growth and differentiation of cells during mammalian embryogenesis has been reviewed in some detail (Hill and Hogg, 1989; Baker et al., 1993).

Beck et al. (1987) and Stylianopoulou et al. (1988) localized IGF-II mRNA transcripts in the developing rodent fetus, by in situ hybridization, to the liver, head mesenchyme, tissues of somitic and lateral mesoderm origin, skeletal muscle and developing cartilage, cardiac mesenchyme and yolk sac mesoderm. Derivatives of embryonic ectoderm, such as the peripheral and central nervous systems, showed no expression, with the exception of the choroid plexus. Lee et al. (1990) demonstrated transient expression of IGF-II transcripts in the primitive endoderm before yolk sac formation, with a subsequent shift in expression to the extraembryonic mesoderm at the primitive streak stage. The embryo itself did not express IGF-II mRNA until the late primitive streak/neural plate stage, when transcripts were localized specifically to the lateral mesoderm, the anterior-proximal cells that participate in the formation of the heart and foregut epithelium, the cranial mesenchyme and the pre-somitic somitic mesoderm. IGF-II expression has also been studied in the human conceptus, in which the first accumulation of IGF-II transcripts is detected between 5 and 18 days after fertilization in the Langhans' layer of trophoblastic villi and the trophoblast layer of the amniotic plate (Brice et al., 1989; Ohlsson et al., 1989). Between 18 days and 14 weeks of gestation, IGF-II gene expression in the human fetus follows a similar tissue-specific pattern to that described in rodent embryogenesis (Brice et al., 1989). In addition to strong IGF-II mRNA expression in the fetal liver and tissues derived from embryonic mesoderm, expression was also intense in the adrenal cortex and metanephric blastema of the kidney, but declined as the level of differentiation in these tissues increased. 
There is considerable evidence that inappropriate expression of IGF-II mRNA is a major factor in the aetiology of several childhood tumours, such as Wilm's tumour (embryonal nephroblastoma), hepatoblastoma and adrenal cortical carcinoma (Scott et al., 1985; Haselbacher et al., 1987). The most direct evidence for a physiological role of IGF-II in embryonic growth comes from IGF-II gene targeting studies. De Chiara et al. (1990, 1991) disrupted one of the IGF-II alleles in cultured mouse embryonic stem cells by mutation and then used the resulting cells to construct chimaeric animals. Transmission of the inactivated IGF-II allele from male chimaeras resulted in heterozygous progeny $40 \%$ smaller than their wild-type littermates. In addition to demonstrating a role for IGF-II in fetal growth, this study showed that only the paternal IGF-II allele is expressed in embryos. Ferguson-Smith et al. (1991) also demonstrated preferential expression of the paternal IGF-II allele in mice, confirming that this gene is maternally imprinted (paternally expressed). Barlow et al. (1991) showed that the IGF-II receptor was paternally imprinted (maternally expressed) in mice.

Expression of IGF-II in placental tissues is well documented in rodents (Beck et al., 1987; Stylianopoulou et al., 1988; Lee et al., 1990). After formation of the yolk sac in the early embryo, IGF-II mRNA is detected in the trophoblast, chorion, visceral yolk sac and allantois. In the later placenta (day 9.5-18.5), it is expressed in vasculogenic mesenchyme derived from the allantois, and in the trophoblast, where expression follows a dynamic pattern reflecting the continuing differentiation of this tissue (Redline et al., 1993). Similar observations have been made in the human placenta by Ohlsson et al. (1989) and Glaser et al. (1992) who found that IGF-II was expressed in the vasculogenic mesenchyme, the early cytotrophoblast shell and the later intermediate and villous trophoblast layers. Lysiak ef al. (1993) studied the effects of IGF-II on the proliferation and invasiveness of first trimester human trophoblast isolated from explants of chorionic villi in vitro. They observed that the ability of the trophoblast to penetrate Matrigel-coated Millipore membranes in transwell invasion chambers increased in a dose-dependent fashion in the presence of increasing concentrations of IGF-II. Furthermore, they demonstrated a modulating effect of IGF-binding protein I (IGFBP-I) on trophoblast invasion in vitro, while Hill et al. (1993) demonstrated, by immunohistochemistry, the presence of IGFBP-I and -2 in the syncytiotrophoblast, intermediate trophoblast, amnion and decidual tissues.

A unique aspect of trophoblast growth and differentiation in horses involves the development, between days 25 and 35 after ovulation, of an annulate band of highly proliferative trophoblast cells called the chorionic girdle (Allen and Moor, 1972). This hyperplastic region of the trophoblast invades the maternal endometrium between days 36 and 38 to form a series of discrete endometrial protuberances called endometrial cups (Allen et al., 1973). Each cup is composed of a densely packed mass of large, binucleate epithelial-type cells of trophoblast origin which secrete chorionic gonadotrophin (eCG) into the maternal blood stream via a complex network of lymph sinuses that develop beneath each cup. The remaining trophoblast is non-invasive and, from day 40-42 onwards, develops an increasingly complex microvillous, microcotyledonary interdigitation with the maternal endometrium to form the true epitheliochorial placenta (Samuel et al., 1974).

In the present study, the techniques of in situ hybridization and northern blotting were used to investigate IGF-II expression in the horse conceptus and, in particular, the extraembryonic membranes, during chorionic girdle development and invasion of the endometrium and during establishment of the epitheliochorial placenta.

\section{Materials and Methods}

\section{Tissues}

Samples of extraembryonic membranes or placenta, the fetus, endometrial cups and biopsies of endometrium, with and without attached placenta, were recovered from 12 pregnant mares on days $14,20,30,33,35,36,38,40,46,60,78$ and 150 after ovulation by two methods. The first, in mares before day 36, involved flushing the unattached, spherical conceptus from the uterus by lavage with $500-1000 \mathrm{ml}$ sterile phosphatebuffered saline $\mathrm{pH} 7.2$ (PBS), via a $14 \mathrm{~mm}$ diameter endotracheal tube passed through the cervix. This was followed by non-surgical endometrial biopsy, as described by Ricketts (1975). The second method involved surgical hysterotomy via ventral midline laparotomy, which was performed under halothane-maintained general anaesthesia in the mares between days 36 and 150 of gestation. Control samples of endometrium, liver and kidney were recovered from two nonpregnant mares post-mortem. For in situ hybridization experiments, tissue samples were snap frozen immediately after removal from the mare and embedded in OCT compound (British Drug Houses, Poole) prior to cryosectioning. For northern blots, approximately I $g$ samples of each tissue were wrapped in aluminium foil, frozen in liquid $\mathrm{N}_{2}$ and stored at $-70^{\circ} \mathrm{C}$ until required for RNA extraction.

\section{Probes}

For both in situ hybridization and northern blot experiments, synthetic sense and antisense oligonucleotide probes (antisense: 5 -AAC TGG AGG GTG TCA CCA GCT CCC CGC CGC ACA GAG TCT CGC TGG-3') were based on a region in exon 4 of the ovine IGF-II gene sequence (O'Mahoney and Adams, 1989). For in situ hybridizations, the probes were labelled with $\alpha^{35} \mathrm{~S}$-[dATP] (1200 Ci mmol ${ }^{-1}$, New England Nuclear, Stevenage) to a specific activity of $>10^{9}$ d.p.m. $\mu \mathrm{g}^{-1}$ using terminal deoxynucleotidyl transferase (Pharmacia, St Albans). For northern blots, they were labelled with $\alpha^{32} \mathrm{P}$-[dCTP] $\left(6000 \mathrm{Ci} \mathrm{mmol}^{-1}\right.$, New England Nuclear) to a specific activity of $10^{10}$ d.p.m. ng ${ }^{-1}$.

\section{In situ hybridization}

Cryostat sections, 7-12 $\mu \mathrm{m}$ thick, were thaw-mounted onto poly-L-lysine coated microscope slides, fixed by immersion in a solution of $4 \%$ (w:v) paraformaldehyde in PBS ( $\mathrm{pH} \mathrm{7.2)} \mathrm{for}$ 5 min, rinsed in PBS, dehydrated in an ethanol series and air-dried. All aqueous solutions were prepared using water that 

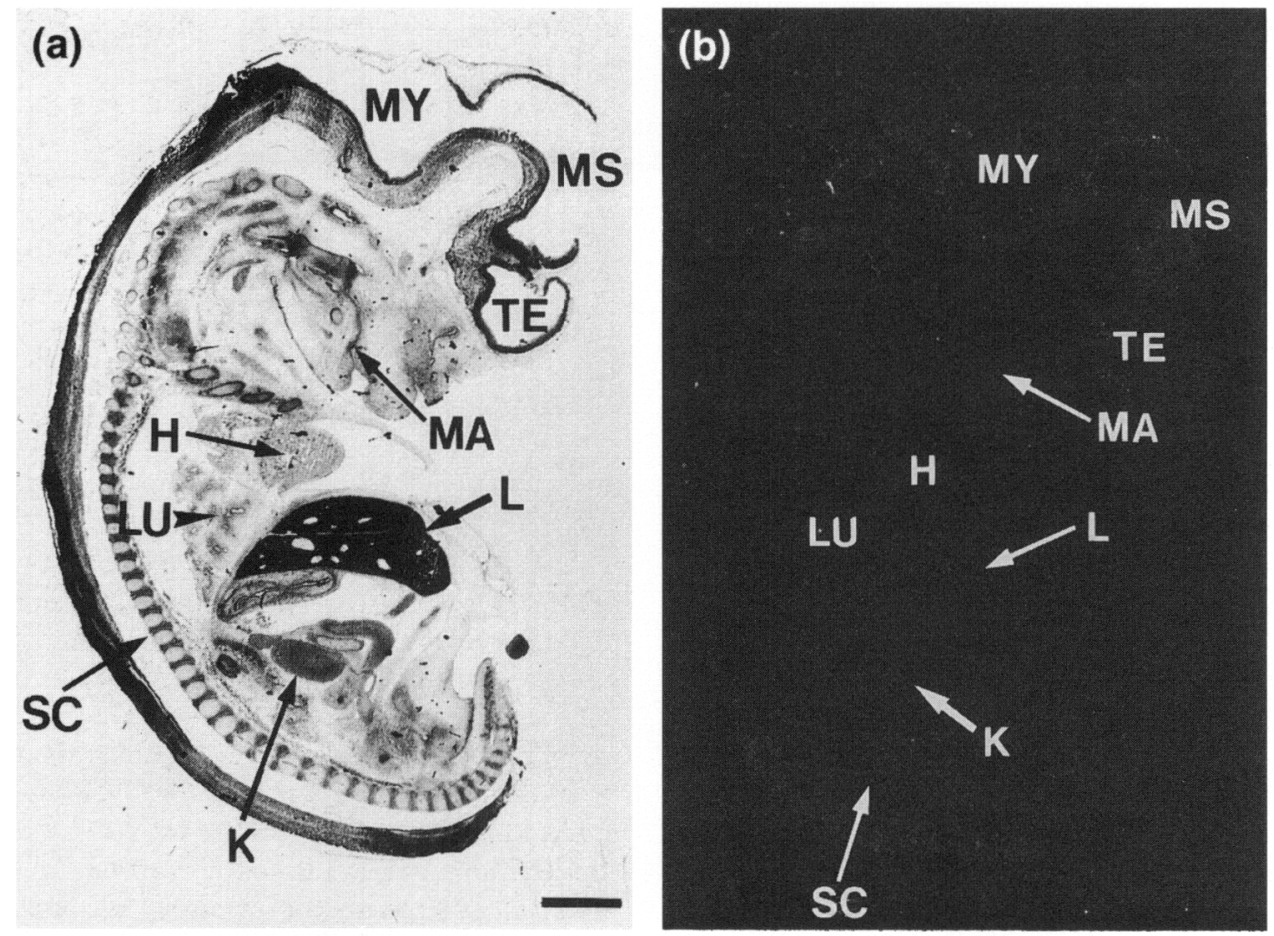

Fig. 1. (a) Bright-field photomicrograph of a section of a day 38 horse fetus, stained with haematoxylin and eosin and (b) a consecutive serial section hybridized to the insulin-like growth factor II (IGF-II) sense (control) oligonucleotide probe. Note the absence of hybridization signal with this probe. $\mathrm{H}$ : heart; K: kidney; L: liver; LU: lung; MA: mandible; MS: mesencephalon; MY: myelencephalon; SC: spinal cord; TE: telencephalon. Scale bar represents $2 \mathrm{~mm}$.

had been treated with $0.1 \%(\mathrm{w}: \mathrm{v})$ diethylpyrocarbonate (DEPC) and autoclaved to destroy ribonuclease enzymes. Hybridization was performed in a buffer consisting of $50 \%(\mathrm{v}: \mathrm{v})$ deionized formamide, $10 \%(\mathrm{w}: \mathrm{v})$ dextran sulphate, $0.3 \mathrm{~mol} \mathrm{NaCl}^{-1}$, $5 \times$ Denhardts reagent (Sambrook et al., 1989), $25 \mathrm{mmol}$ sodium phosphate $\mathrm{I}^{-1}(\mathrm{pH} 6.8)$, $100 \mathrm{ng}$ polyadenylic acid $\mathrm{ml}^{-1}, 0.5 \mathrm{mg}$ salmon testes DNA ml ${ }^{-1}$ and $50 \mathrm{mmol} \mathrm{di-}$ thiothreitol $\mathrm{I}^{-1}$. Each labelled probe was diluted in buffer to a concentration of $3 \times 10^{3}$ d.p.m. $\mu \mathrm{l}^{-1}$, and $100 \mu \mathrm{l}$ of this solution was applied to each slide followed by incubation at $42^{\circ} \mathrm{C}$ for a minimum of $16 \mathrm{~h}$. The slides were then washed in a solution of $1 \times$ SSC ( $150 \mathrm{mmol}$ sodium chloride $1^{-1}, 15 \mathrm{mmol}$ trisodium citrate $\left.\mathrm{I}^{-1}, \mathrm{pH} 7.0\right)$ containing $0.1 \%(\mathrm{w}: \mathrm{v})$ sodium thiosulphate, once for $45 \mathrm{~min}$ at room temperature and again for $45 \mathrm{~min}$ at $50^{\circ} \mathrm{C}$. They were then rinsed for $5 \mathrm{~min}$ in $0.1 \times \mathrm{SSC}$ and dehydrated sequentially in $50 \%, 70 \%$ and $95 \%$ (v:v) ethanol, before being air-dried. After initial X-ray film autoradiography, the sections were coated with a $1: 2$ dilution of Ilford $\mathrm{K} 5$ photoemulsion, air-dried and exposed for 2 weeks in a light-proof box containing silica gel. Finally, the slides were developed in phenisol developer (Ilford Ltd, Mobberley), fixed and stained with haematoxylin and eosin.

\section{Northern blot analysis}

Total RNA was isolated from I g samples of each tissue by the method of Chomczynski and Sacchi (1987). Approximately
$20 \mu \mathrm{g}$ of total RNA from each tissue was then fractionated together with RNA molecular size markers (Gibco BRL, Paisley), on a $1 \%$ ( $w: v)$ agarose-formaldehyde gel and transferred to a nylon membrane (Hybond $\mathrm{N}$; Amersham International, Amersham). The membrane was pre-hybridized for $2 \mathrm{~h}$ with approximately $8 \mathrm{ml}$ of the in situ hybridization buffer described above. Labelled oligonucleotide probe was then added to the hybridization buffer at a concentration of $3 \times 10^{3}$ d.p.m. $\mu \mathrm{l}^{-1}$ for hybridization at $42^{\circ} \mathrm{C}$ for $16 \mathrm{~h}$. Filters were washed 3-4 times in $2 \times \mathrm{SSC}, 0.1 \%(\mathrm{w}: \mathrm{v})$ sodium dodecylsulphate (twice at room temperature and at least once at $45^{\circ} \mathrm{C}$ ) before being exposed to X-ray film (X-OMAT; Kodak) at $-70^{\circ} \mathrm{C}$ for between $16 \mathrm{~h}$ and 3 days.

\section{Results}

In situ hybridization

The antisense oligonucleotide probe demonstrated stable, highly localized hybridization patterns exclusively in tissues of fetal origin and the results are summarized in Figs 1-5. At no stage was hybridization of the antisense probe detected in the maternal endometrium. Furthermore, the sense control probe produced no specific hybridization to any tissue at any stage (Fig. 1).

In the fetus, expression of mRNA encoding IGF-II, as revealed by hybridization of the antisense probe, was detected in a diversity of cell types at all stages studied (Fig. 2). Early 
(a)

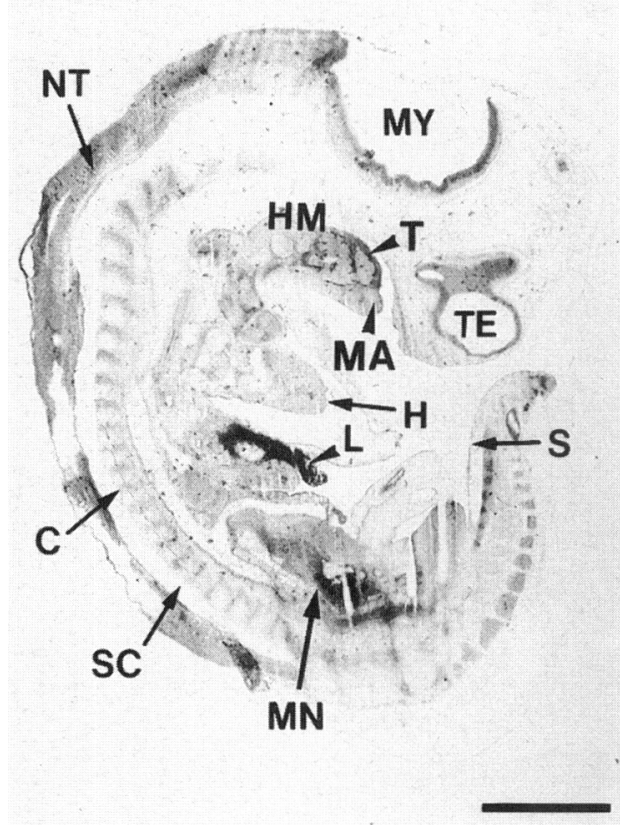

(c)

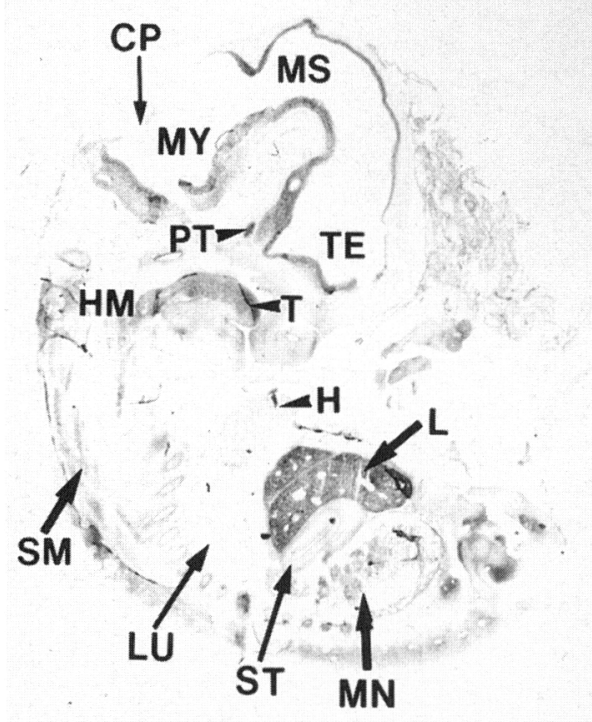

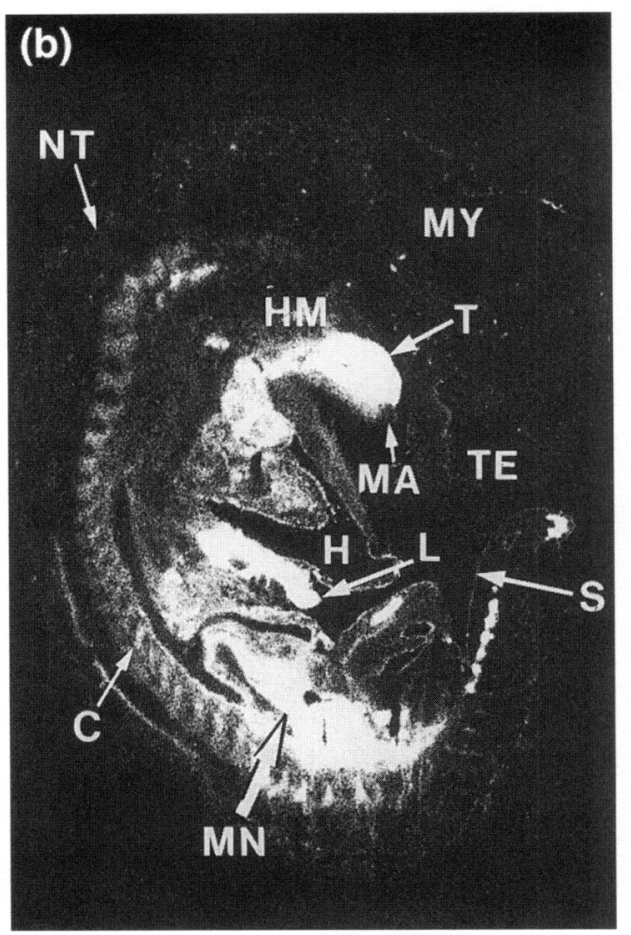

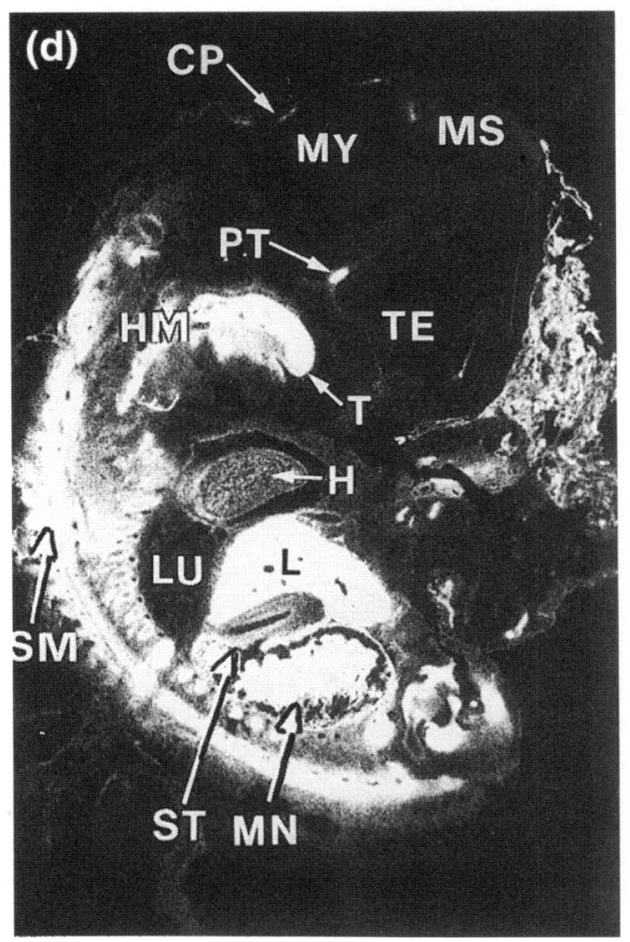

Fig. 2. (a)-(d). embryonic somites consisted of blocks of mesodermal cells lying along each side of the neural tube. By day 30 after ovulation, the processes of somitic differentiation were well established and high concentrations of mRNA encoding IGF-II were detected in the sclerotome-derived chondrocytes of the early spinal cord and head mesenchyme, and in the skin, tongue, liver and mesonephros (Fig. 2a, b). At day 35 (Fig. 2c, d) and 38 (Fig. 2e, $\mathrm{f}$ ), the expression of mRNA IGF-II in the cartilage-forming cells of the developing skeleton had increased and was also evident in the myotome-derived striated muscle components. By day 46 (Fig. 2g, h), fetal organogenesis was complete and expression of IGF-II transcripts in dermatome- and myotome-derived tissues, such as the skin and skeletal muscle, was still intense. However, in the ossifying chondrocytes of the peripheral skeleton, expression was declining by this stage. 
(e)

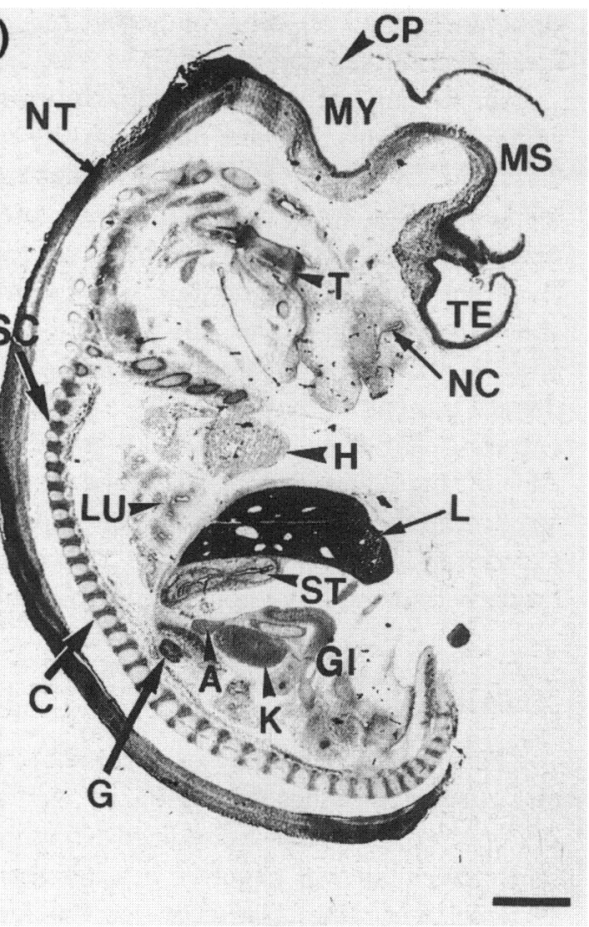

\section{(g)}

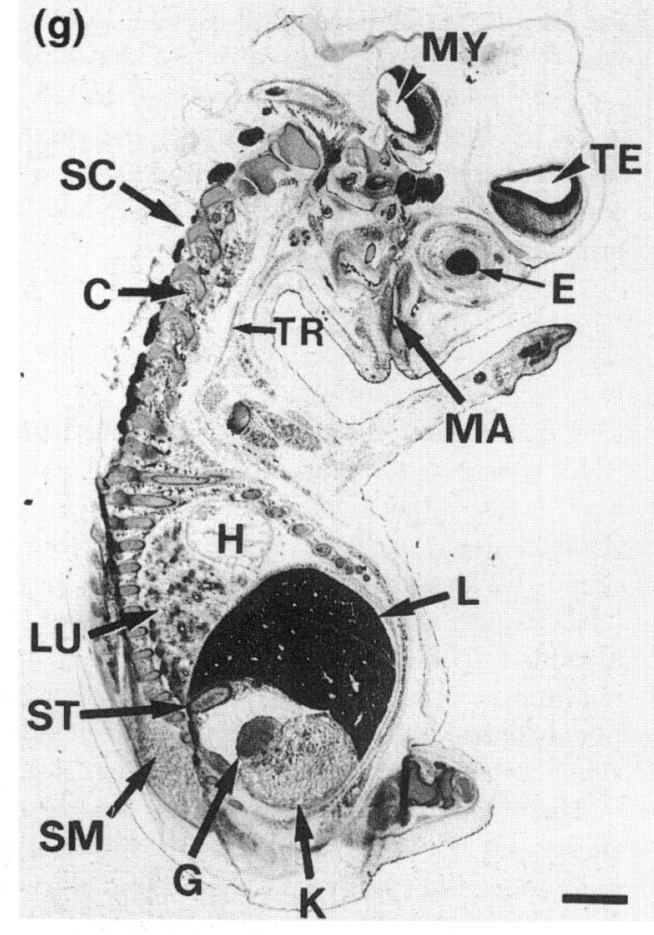

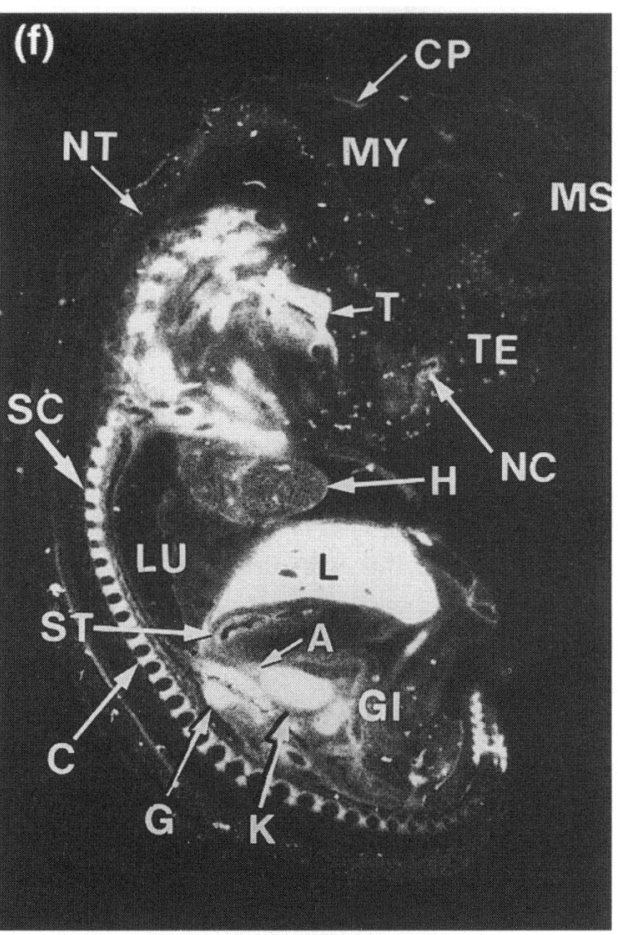

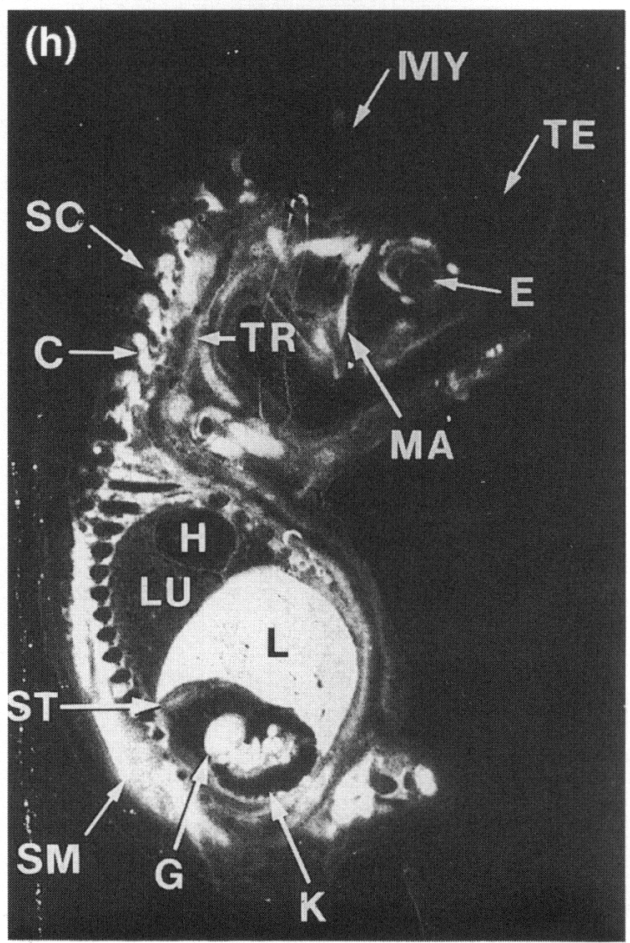

Fig. 2. (e)-(h).

Fig. 2. In situ hybridization analysis of insulin-like growth factor II (IGF-II) gene expression in the developing horse fetus. (a) Bright-field photomicrograph of a section of a day 30 horse fetus hybridized to the IGF-II antisense probe, exposed to photographic emulsion and stained with haematoxylin and eosin. (b) Dark-field photomicrograph of the same section illustrating the hybridization signal. (c) and (d) Bright- and dark-field photomicrographs, respectively of a section of a day 35 fetus hybridized to the IGF-II antisense probe. (e) and (f) Bright- and dark-field photomicrographs of a section of a day 38 fetus hybridized to the IGF-II antisense probe. $(\mathrm{g})$ and $(\mathrm{h})$ Bright-and dark-field photomicrographs of a section of a day 46 fetus hybridized to the IGF-II antisense probe. Note the strong hybridization signal, predominantly in tissues of mesodermal origin, but also in the endoderm-derived liver and ectoderm-derived skin and skeletal muscle. Note also the general lack of signal in the brain. A: adrenal; C: chondrocytes; CP: choroid plexus; E: eye; G: gonad; Gl: gastro-intestinal tract; H: heart; HM: head mesenchyme; K: kidney; L: liver; LU: lung; MA: mandible; MN: mesonephros; MS: mesencephalon; MY: myelencephalon; NC: nasal canal; NT: neural tube; PT: pituitary; S: skin; SC: spinal cord; SM: skeletal muscle; ST: stomach; T: tongue; TE: telencephalon; TR: trachea. Scale bars represent $2 \mathrm{~mm}$. 
Tissues derived from intermediate mesoderm, such as the urogenital system, also expressed high levels of IGF-II mRNA. At days 30 and 35 after ovulation, expression was intense in the mesonephros (Fig. 2a-d) and at days 38 and 46, high concentrations of IGF-II mRNA were detected in the presumptive gonads and kidney (Fig. 2e-h). Lateral mesoderm derivatives, such as the pericardium, epimyocardium and endocardium of the heart, expressed IGF-II transcripts at all stages studied but the amount was reduced in the day 46 fetus (Fig. $2 \mathrm{~g}, \mathrm{~h}$ ). The adrenal cortex, also a derivative of the lateral mesoderm expressed high levels of IGF-II mRNA (Fig. 2e, $\mathrm{f}$ ), as did the fetal kidney (Fig. 2e-h).

The distribution of IGF-II transcripts in ectodermal derivatives was not so widespread. They were not found in derivatives of the neural tube, with the exception of the choroid plexus (Fig. 2e, $\mathrm{f}$, whereas head and facial mesenchyme, which contribute to the formation of the maxilla, palate, mandible, facial and orbital cartilage and tongue, were intensely labelled at all stages. In contrast, the neural crest-derived cranial sensory ganglia surrounding the myelencephalon, mesencephalon and telencephalon, failed to show expression at any stage. In the section of the day 35 fetus (Fig. 2c,d), the fetal pituitary gland was evident and demonstrated high IGF-II gene expression.

In tissues of endodermal origin, IGF-Il gene expression was similarly confined to specific tissue types, such as the liver, where at all stages studied, the expression was very high. Furthermore, expression of mRNA encoding IGF-II in the fetal liver was diffuse and not confined to one particular cell type. A much lower expression was exhibited by the epithelial cells of the trachea, lung bronchioles and gastrointestinal tract (Fig. 2c-h).

The in situ hybridization results on the extraembryonic membranes are summarized in Figs 3-5. In the pre-implantation conceptuses, no IGF-II gene expression was detected in the early yolk sac endoderm or outer trophoblast layers at day 14 (Fig. 3a, b) but from day 20, expression was intense in the vascularized mesoderm developing between the inner endoderm and outer trophoblast cell layers (Fig. 3c, d) and at day 36 , in the cells of the developing chorionic girdle (Fig. 3e, f). At this stage, the non-invasive trophoblast of the allantochorion exhibited no hybridization, illustrating a marked difference between the invasive (chorionic girdle) and non-invasive components of trophoblast. After invasion of the chorionic girdle into the endometrium at day 36-38, the resulting binucleate endometrial cup cells continued to express high amounts of mRNA encoding IGF-II (Fig. 4). The day 46 endometrial cup (Fig. $4 \mathrm{a}, \mathrm{b}$ ) consisted of large, healthy IGF-II-positive binucleate cup cells surrounded by maternal lymphocytes. The adjacent normal allantochorion, not present in this section, was already becoming attached to the endometrial epithelium at this stage (see Fig. 5a,b). Figure $4 \mathrm{~g}$ and $\mathrm{h}$ illustrate the day 46 endometrial cup at a higher magnification, to show several IGF-II-negative maternal endometrial glands surrounded by IGF-II-positive fetal cup cells. In the day 60 specimen, the allantochorion was firmly attached to the endometrium and was strongly positive and the large fetal endometrial cup cells were also positive. However, by day 80 (Fig. $4 \mathrm{e}, \mathrm{f}$ ), the endometrial cup region had become negative owing to degeneration and necrosis of the fetal cup cells and the commencement of sloughing of the necrotic cup from the surface of the endometrium.

Examination of placental development away from the endometrial cups showed that both the non-invasive trophoblast and the underlying mesenchymal tissue demonstrated a marked upregulation of IGF-II gene expression during formation and interdigitation of the chorioallantoic placenta (Fig. 5). From the earliest interdigitation between the allantochorion and luminal epithelium of the endometrium at day 46 (Fig. 5a, b) to the development of the complex microcotyledonary placenta at day 150 (Fig. $5 \mathrm{~g}, \mathrm{~h}$ ), the amount of mRNA encoding IGF-II in the placental membranes remained high. At no stage was any IGF-II gene expression exhibited by any component of the maternal endometrium, and IGF-II expression, therefore, provided an accurate marker of fetal tissue within the developing horse placenta.

\section{Northern blots}

The northern blot analyses of total RNA extracted from fetal and maternal tissues is illustrated in Fig. 6. The antisense oligonucleotide probe hybridized to multiple transcripts in all fetal tissues but was negative in adult tissues (for example, the endometrium; lane 2) except for the kidney, in which two transcripts were evident (lane 1). The most intense gene expression was demonstrated by fetal liver on day 78 (lane 4) where a total of 7 transcripts $(6.2 \mathrm{~kb}, 4.0 \mathrm{~kb}, 3.5 \mathrm{~kb}, 2.8 \mathrm{~kb}$, $2.05 \mathrm{~kb}, 1.4 \mathrm{~kb}$ and $1.3 \mathrm{~kb}$ ) were detected. Expression was lower in other fetal tissues (for example, muscle; lane 3 ). These results were consistent with studies in other species and confirmed the specificity of the ovine IGF-II oligonucleotide probe for equine IGF-II mRNA.

\section{Discussion}

Our demonstration of seven IGF-II transcripts in horse fetal RNA concurs with similar findings in sheep fetuses, in which ten major transcripts of $6.2-1.3 \mathrm{~kb}$ were identified (O'Mahoney et al., 1992), in the rat fetus where four transcripts of 6.0-1.2 kb were detected (Brown et al., 1986) and in human fetal tissues in which five transcripts of $6.0-1.8 \mathrm{~kb}$ were identified (LeBouc et al., 1987). Expression of IGF-II as a multitranscript family suggests a complex pattern of transcriptional control of this growth factor, which may have functional significance during development (Brown et al., 1986).

The in situ hybridization results in the horse fetus agree with studies on IGF-II gene expression during rodent and human embryogenesis (Beck et al., 1987; Stylianopoulou et al., 1988; Brice et al., 1989) and suggest that, as in other species, IGF-II acts as an autocrine or paracrine mitogen for a variety of tissues during embryogenesis. The greatly reduced body size of mice carrying a paternally inherited mutated allele of the IGF-II gene (DeChiara et al., 1991) and the increased growth of fetal mice with a duplication of the paternal IGF-II allele (Fergusson-Smith et al., 1991) also support a mitogenic role for IGF-II in embryogenesis and placental growth and development.

IGF-II was expressed in the extraembryonic membranes of the horse conceptus in a developmentally regulated manner and showed a clear correlation with the unusual events of 

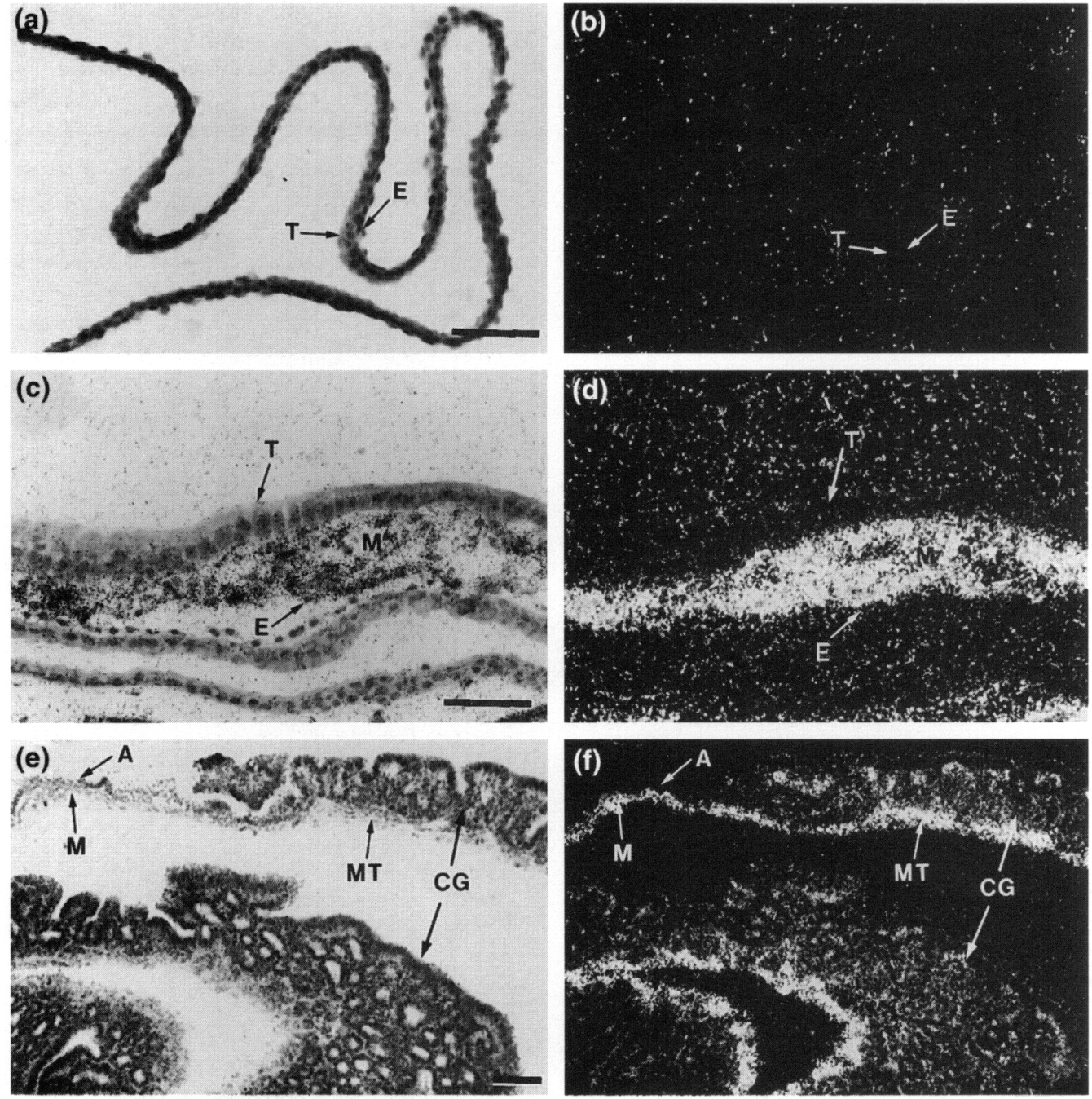

Fig. 3. Bright- and dark-field photomicrographs illustrating the in situ hybridization analysis of insulin-like growth factor II (IGF-II) gene expression in the extraembryonic membranes of the horse conceptus. There is no positive hybridization in the endoderm (E) or trophoblast (T) layers at day 14 after ovulation (a, b). At day 20, a high level of IGF-II expression is evident in the vascularized mesoderm (M) developing between the endoderm and outer trophoblast layers $(c, d)$. By day $36(e, f)$, IGF-II gene expression is localized to the mesoderm of the allantochorion (A), to the proliferating invasive trophoblast cells of the chorionic girdle (CG) and to the underlying mesothelium (MT). Note the absence of expression in the trophoblast layer of the non-invasive allantochorion (A). Scale bars represent $20 \mu \mathrm{m}$.

placentation in this species. The strong expression observed in the chorionic girdle before its invasion of the endometrium is comparable to the high IGF-II expression in human intermediate trophoblast and murine glycogen cells and may be analogous to the IGF-II autocrine stimulatory loop thought to be fundamental to the development of the invasive human placenta (Ohlssen et al., 1989; Glaser et al., 1992; Redline et al., 1993). Likewise, the intense expression of IGF-II in the vascularized allantois of the allantochorion from day 20 onwards appears analogous to that observed in the vasculogenic mesenchyme and villous stroma of human and mouse conceptuses. Furthermore, expression in non-invasive trophoblast cells from day 46 onwards correlates with expression of IGF-II in the cytotrophoblast layer of human villous trophoblast, and in the three-layered labyrinthine trophoblast of mice.
In equids, development of the chorionic girdle between days 25 and 35 after ovulation involves a rapid and unusual multiplication of trophoblast cells to form long finger-like processes of hyperplastic cells. This development is very discrete and is strictly limited to the area of trophoblast that overlies the point of abutment of the developing allantois and the regressing yolk sac (van Niekerk and Allen, 1975). In this region, the trophoblast has no adjacent vascular mesoderm but, instead, has an underlying compartment bordered on one side by the yolk sac mesoderm and on the other by the allantoic mesoderm (Enders and Liu, 1991). Hence, the marked upregulation of IGF-Il gene expression observed in the trophoblast cells of the chorionic girdle may be related to the absence of underlying mesoderm in this area. It is possible that the vascular mesoderm produces a factor 

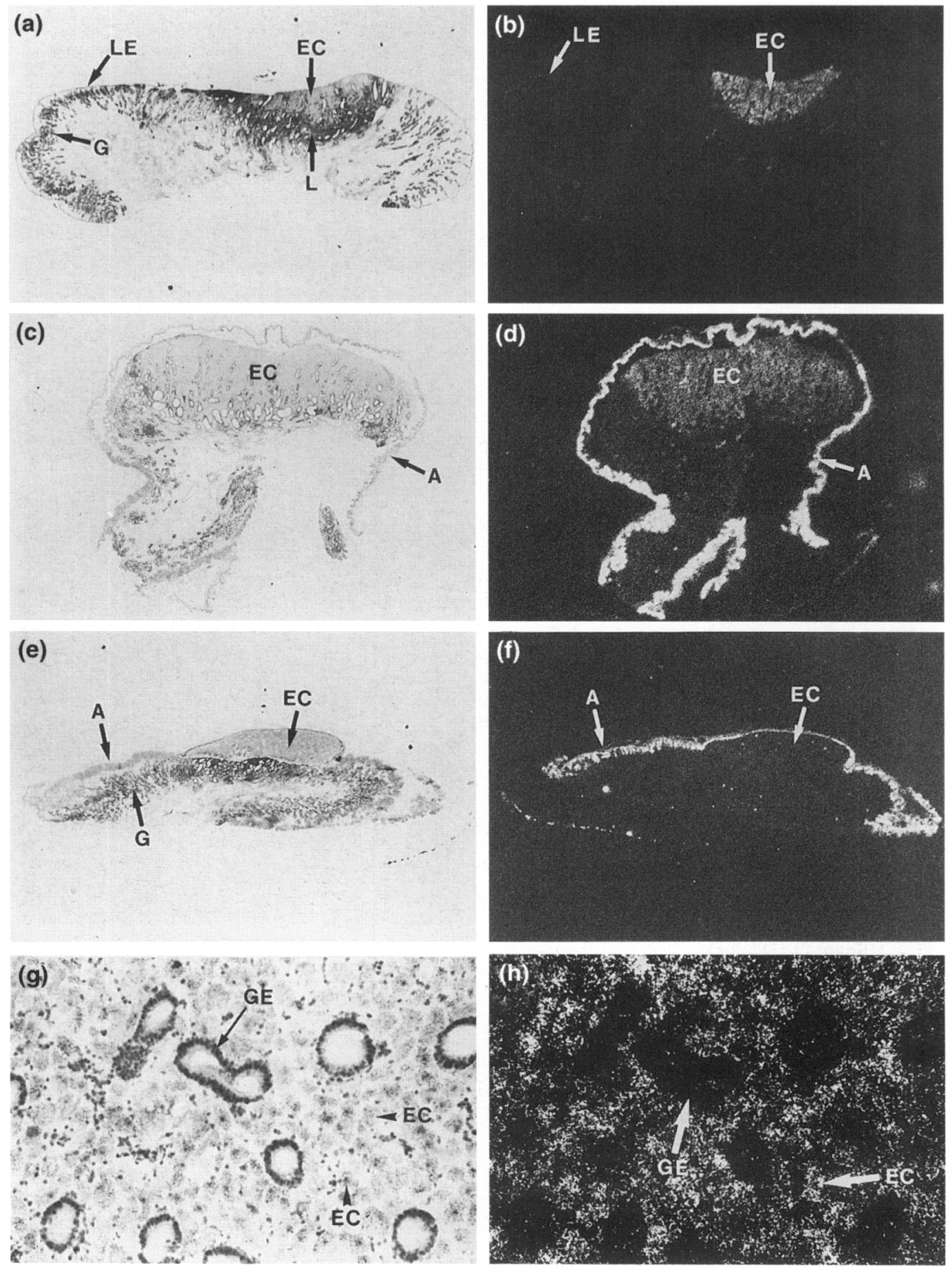

Fig. 4. Bright- and dark-field photomicrographs illustrating the in situ hybridization analysis of insulin-like growth factor II (IGF-II) gene expression in the endometrial cups and surrounding maternal endometrium at days 46 $(\mathrm{a}, \mathrm{b}, \mathrm{g}, \mathrm{h}), 60(\mathrm{c}, \mathrm{d})$ and $80(\mathrm{e}, \mathrm{f})$ after ovulation. A high concentration of mRNA encoding IGF-II is present in endometrial cup cells (EC) at days 46 and 60 but, by day 80 , the level of expression had declined due to necrosis of the cup cells. Expression is also strong in the allantochorion $(A)$ at day 60 and day 80 , but absent in the maternal endometrium. $(\mathrm{g})$ and $(\mathrm{h})$ are higher power photomicrographs of the day 46 endometrial cup showing expression of IGF-II in the fetal cup cells but no expression in the maternal endometrial glands. G: endometrial glands; GE: glandular epithelium; LE: Juminal epithelium; L: lymphocytes. Scale bars represent $2 \mathrm{~mm}(\mathrm{a}-\mathrm{f})$ and $20 \mu \mathrm{m}(\mathrm{g}, \mathrm{h})$.

capable of inhibiting this type of trophoblast proliferation, operating over the majority of the conceptus, which is unable to reach and affect the area upon which the chorionic girdle develops. The result of this is that the trophoblast in this area can respond to a stimulus of maternal or fetal origin, leading to upregulation of IGF-II gene expression 

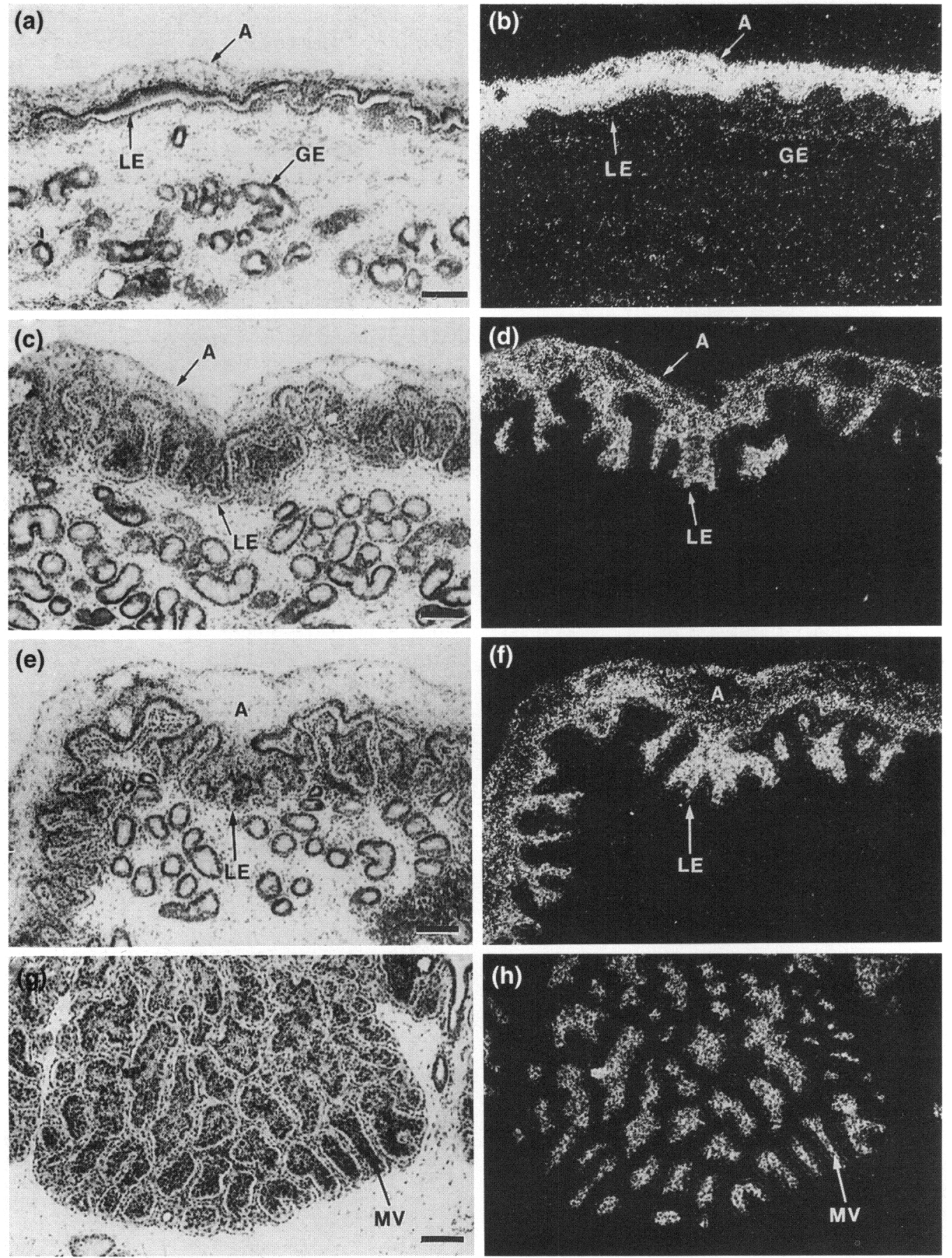

Fig. 5. Bright- and dark-field photomicrographs illustrating the in situ hybridization analysis of insulin-like growth factor II (IGF-II) gene expression in the non-invasive placenta at day 46 (a, b), day 60 (c, d), day 80 (e, f) and day $150(\mathrm{~g}, \mathrm{~h})$ after ovulation. At all stages of development, from the commencement of interdigitation with the maternal endometrium at day 46 to the establishment of the branched microvilli (MV) of the mature microcotyledon at day 150, both the trophoblast and allantoic mesenchyme layers of the allantochorion (A) express high levels of IGF-II mRNA. No IGF-II gene expression is evident in the luminal epithelium (LE), glandular epithelium (GE) or endometrial stroma. Scale bars represent $20 \mu \mathrm{m}$.

and a switch to invasiveness. Since it is possible to grow horse chorionic girdle cells in tissue culture (Allen and Moor, 1972) and test their invasive properties in vitro (Meadows et al., in press) it would be interesting to examine whether IGF-II can stimulate this invasiveness in vitro in a dose-dependent manner, as has been demonstrated for human extravillous intermediate trophoblast cells by Lysiak et al. (1993). 

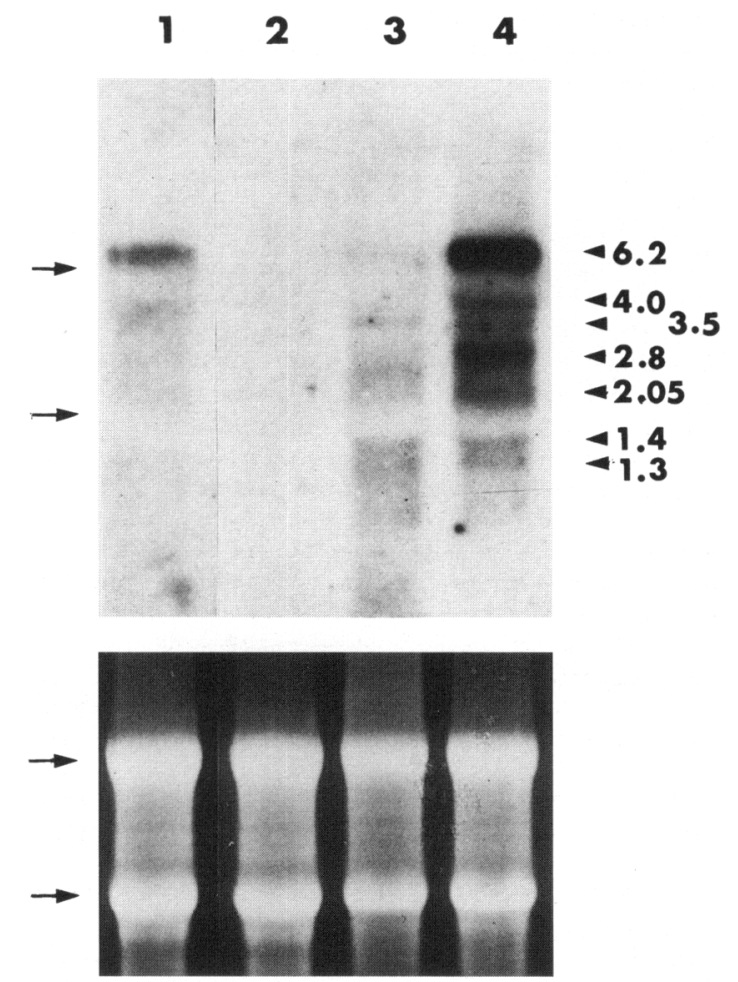

Fig. 6. Northern blot analysis of insulin-like growth factor II (IGF-II) gene expression in horse adult and fetal tissues using the ovine IGF-II antisense oligonucleotide probe. The probe hybridized to a total of seven franscripts (6.2-1.3 kb, arrowheads) in fetal liver (lane 4), and muscle (lane 3), was negative in maternal endometrium (lane 2), and hybridized to two transcripts (6.2 and $4.0 \mathrm{~kb}$ ) in adult kidney (lane 1 ). The lower panel shows the ethidium bromide-stained RNA prior to transfer and photographed under UV illumination. Arrows on the left indicate the $28 \mathrm{~S}$ and $18 \mathrm{~S}$ ribosomal RNA bands on the ethidium bromide stained gel and also their position on the blot.

Growth regulation in early mammalian conceptuses may involve parental gene imprinting that results in selective, differential expression of growth factor genes. Furthermore, in the case of IGF-II, reciprocal imprinting occurs, where the paternal allele of the growth factor and the maternal allele of its receptor are expressed (Di Chiara et al., 1991; Barlow et al., 1991). Paradoxically, the mitogenic actions of IGF-II appear not to function through its own high-affinity receptor, but through the type I IGF receptor, at least in the embryo. However, Baker ef al. (1993) propose that a third, unknown IGF receptor may be responsible for IGF-II stimulation of placental growth.

In horse placentation, the width and overall development of the progenitor chorionic girdle, and hence the size and secretory activity of the resulting endometrial cups, appear to be determined by paternal genotype. Studies in mares and Jenny donkeys carrying intraspecies horse and donkey pregnancies, or interspecies mule and hinny pregnancies, revealed that when the sire is a horse (horse and hinny conceptuses), a broad, thick chorionic girdle develops on the conceptus, giving rise to large, active endometrial cups. However, when the sire is a donkey (donkey and mule conceptuses), the girdle and resulting endometrial cups are significantly smaller (Allen, 1975; Stewart and Allen, 1981). This marked effect of paternal genotype is strongly influenced by uterine environment, as was demonstrated by using embryo transfer to create extraspecies horse pregnancies. Transfer of a horse embryo to the uterus of a Jenny donkey results in a broad girdle and large, active endometrial cups, whereas transfer of a donkey embryo to a horse recipient produces an exceptionally narrow girdle that fails completely to invade the maternal endometrium to form cups (Allen, 1982; Allen et al., 1987). Transfer of an interspecies mule embryo, which would normally produce a narrow chorionic girdle, into the uterus of a Jenny donkey results in the development of a very large and active chorionic girdle, giving rise to endometrial cups typical of those seen in a donkey carrying an interspecies hinny conceptus (Allen et al., 1993). To explain this apparent conflict between paternal genotype and uterine environment, we proposed reciprocal genomic imprinting of a growth factor and its receptor interacting with a negative uterine factor that is greater in the horse than in the donkey (Allen et al., 1993). Our findings in this study offer the possibility that the reciprocally imprinted growth factor and receptor might be, respectively, IGF-II and the placentalspecific IGF-II receptor proposed by Baker et al. (1993), with one of the IGF-binding proteins constituting the inhibitory uterine factor. The ability to create hybrid pregnancies in equids facilitates studies on specific gene imprinting and experiments are underway to determine whether the equine IGF-II gene is imprinted.

In conclusion, IGF-II is widely expressed in equine fetal tissues, and probably stimulates a wide diversity of cell types during development. In addition, it is possibly influenced by genomic imprinting and may be intrinsic to the development of both the invasive chorionic girdle and the non-invasive trophoblast that lines the outer surface of the definitive allantochorionic placenta in mares.

The authors thank J. Cripps and R. S. Gilmour, The Babraham Institute, Cambridge, UK for the sense and antisense IGF-II oligonucleotide probes. This work was supported by the Thoroughbred Breeders' Association of Great Britain and the Agricultural and Food Research Counci! (LRG8/309).

\section{References}

Allen WR (1975) The influence of fetal genotype upon endometrial cup development and PMSG and progestagen production in equids Journal of Reproduction and Fertility Supplement 23 441-445

Allen WR (1982) Immunological aspects of the endometrial cup reaction and the effects of xenogeneic pregnancy in horses and donkeys Journal of Reproduction and Fertility Supplement 31 57-94

Allen WR and Moor RM (1972) The origin of the equine endometrial cups I: Production of PMSG by fetal trophoblast cells Journal of Reproduction and Fertility 29 313-316

Allen WR, Hamilton DW and Moor RM (1973) The origin of the equine endometrial cups II: Invasion of the endometrium by trophoblast Anatomical Record 177 485-501

Allen WR, Kydd JH, Boyle MS and Antczak DF (1987) Extraspecific donkey-inhorse pregnancy as a model of early fetal death Journal of Reproduction and Fertility Supplement 35 197-209

Allen WR, Skidmore JA, Stewart F and Antczak DF (1993) Effects of fetal genotype and uterine environment on placental development in equids Journal of Reproduction and Fertility 98 55-60

Baker J, Liu J-P, Robertson EJ and Efstratiadis A (1993) Role of insulin-like growth factors in embryonic and post-natal growth Cell 75 73-82 
Barlow DP, Stoger R, Hermann BG, Saito K and Schweifer N (1991) The mouse insulin-like growth factor type-2 receptor is imprinted and closely linked to the Tme locus Nature 349 84-87

Baxter RC and Martin JL (1989) Binding proteins for the insulin-like growth factors: structure, regulation and function Progress in Growth Factor Research $149-68$

Beck F, Samani NH, Penschow JD, Thorley B, Tregear GW and Coghlan JP (1987) Histochemical localization of IGF-I and -II mRNA in the developing rat embryo Development 101 175-184

Brice AL, Cheetham JE, Bolton VN, Hill NCW and Schofield PN (1989) Temporal changes in the expression of the insulin-like growth factor II gene associated with tissue maturation in the human fetus Development 106 543-554

Brown AL, Graham DE, Nissley SP, Hill DJ, Strain AJ and Rechler MM (1986) Developmental regulation of insulin-like growth factor II mRNA in different rat tissues Journal of Biological Chemistry 261 13144-13150

Chomczynski P and Sacchi N (1987) Single step method of RNA isolation by acid guanidinium thiocyanate-phenol-chloroform extraction Analytical Biochemistry 162 156-159

DeChiara TM, Efstratiadis A and Robertson EJ (1990) A growth deficiency phenotype in heterozygous mice carrying an insulin-like growth factor II gene disrupted by targeting Nature 345 78-80

DeChiara TM, Robertson EJ and Efstratiadis A (1991) Parental imprinting of the mouse insulin-like growth factor II gene Cell 64 849-859

Enders AC and Liu IKM (1991) Trophoblast-uterine interactions during equine chorionic girdle maturation, migration and transformation American joumal of Anatomy 191 366-381

Fergusson-Smith AC, Cattanach BM, Barton SC, Beechey CV and Surani MA (1991) Embryological and molecular investigations of parental imprinting on mouse chromosome 7 Nature $351667-670$

Glaser A, Luthman H, Stern I and Ohlsson R (1992) Spatial distribution of active genes implicated in the regulation of insulin-like growth factor stimulatory loops in human decidual and placental tissue of first-trimester pregnancy Molecular Reproduction and Development 33 7-15

Haselbacher GK, Irminger JC, Zapf J, Ziegler WH and Humbel RE (1987) Insulin-like growth factor II in human adrenal pheochromocytomas and Wilms' tumour: expression at the mRNA and protein level Proceedings of the National Academy of Sciences USA 1104-1106

Hill DJ and Hogg J (1989) Growth factors and the regulation of pre- and post-natal growth Balliére's Clinical Endocrinology and Metabolism 3 579-625

Hill DJ, Clemmons DR, Riley SC, Bassett N and Challis JRG (1993) Immunohistochemical localization of insulin-like growth factors (IGFs) and IGF binding proteins- $1,-2$ and -3 in human placenta and fetal membranes Placenta 14 $1-12$

Humbel RE (1990) Insulin-like growth factors I and II European Journal of Biochemistry $190445-462$
LeBouc Y, Noguiez P, Sondermeijer P, Dreyer D, Giraro F and Binoux M (1987) A new 5 -non-coding region for human placental insulin-like growth factor II mRNA expression Federation of European Biochemical Societies Letters 222 181-185

Lee JE, Pintar J and Efstratiadis A (1990) Pattern of insulin-like growth factor II gene expression during early mouse embryogenesis Development 110 151-159

Lysiak JJ, Han VKM and Lala PK (1993) Role of insulin-like growth factor (IGF)-II on human first trimester trophoblast cell growth and invasion Placenta 14 A.46

Meadows SJ, Allen WR and Antczak DF (1995) Factors affecting the maturation and invasiveness in vitro of chorionic girdle cells of different genotypes Biology of Reproduction Monograph Series 1 (in press)

Ohlsson R, Holmgren L, Glaser A, Szpecht A and Pfeifer-Ohlsson S (1989) Insulin-like growth factor 2 and short-range stimulatory loops in control of human placental growth EMBO Journal 8 1993-1999

O'Mahoney JV and Adams TE (1989) Nucleotide sequence of an ovine insulinlike growth factor II cDNA Nucleic Acids Research 175392

O'Mahoney JV, Brandon MR and Adams TE (1992) Developmental and tissuespecific regulation of ovine insulin-like growth factor II (IGF-II) mRNA expression Molecular and Cellular Endocrinology 78 87-96

Redline RW, Chernicky CL, Tan H-Q, Ilan J and Ilan J (1993) Differential expression of insulin-like growth factor II in specific regions of the late (post day 9.5) murine placenta Molecular Reproduction and Development 36 121-129

Ricketts SW (1975) Endometrial biopsy as a guide to diagnosis of endometrial pathology in the mare Journal of Reproduction and Fertility Supplement 23 341-345

Sambrook J, Fritsch EF and Maniatis T (1989) Molecular cloning: a laboratory manual Cold Spring Harbor Laboratory Press, New York

Samuel CA, Allen WR and Steven DH (1974) Studies on the equine placenta I: development of the microcotyledons Journal of Reproduction and Fertility 41 441-445

Scott J, Cowell J, Robertson ME, Priestley LM, Wadey R, Hopkins B, Pritchard J, Bell GI, Rall LB, Graham CF and Knott TJ (1985) Insulin-like growth factor II gene expression in Wilms' tumour and embryonic tissues Nature 317 260-262

Stewart F and Allen WR (1981) Biological functions and receptor binding activities of equine chorionic gonadotrophins Journal of Reproduction and Fertility 62 527-536

Stylianopoulou F, Efstratiadis A, Herbert J and Pintar J (1988) Pattern of insulin-like growth factor II gene expression during rat embryogenesis 103 497-506

van Niekerk CH and Allen WR (1975) Early embryonic development in the horse Journal of Reproduction and Fertility Supplement 23 495-498 